\title{
Mean Age of Death, Longevity and Incidence of Violent Death Among Various Elite Sportsmen Categories \\ Anisimov $\mathrm{VN}^{1 *}$ and Zharinov $\mathrm{GM}^{2}$ \\ ${ }^{1}$ Department of Carcinogenesis and Oncogerontology, N.N. Petrov National Medical Research Center of Oncology, St. Petersburg, Russia \\ ${ }^{2}$ A.M. Granov Russian Scientific Center for Radiology and Surgery Technologies, St. Petersburg, Russia
}

*Corresponding author: Anisimov VN, Department of Carcinogenesis and Oncogerontology, N.N. Petrov National Medical Research Center of Oncology, St. Petersburg, Russia, Tel: +7 81243995 34; E-mail: aging@mail.ru

Received: November 28, 2017; Accepted: December 01, 2017; Published: December 04, 017

Copyright: (c) 2017 Anisimov VN, et al. This is an open-access article distributed under the terms of the Creative Commons Attribution License, which permits unrestricted use, distribution, and reproduction in any medium, provided the original author and source are credited.

\section{Editorial}

There is common opinion that moderate intensity physical activity during leisure time is associated with reduced mortality in general population $[1,2]$. During last years considerable attention was paid to the athlete life span and longevity [2-7]. It was shown that some elite sportsmen live longer however another sportsman live shortly than people does not involved big sport. These contradictions could be depending on variability of material for investigations of parameters of life span, type of selection groups of different sport and many other factors. $65 \%$ to $70 \%$ of rate of aging and longevity of humans determined by social and economic conditions and life style [1] whereas genetic factors have an important but significantly smaller impact on aging [8]. Lorry drivers, miners, seamen, and some other professionals have a feature of accelerated aging and increased risk of premature death [6]. At the same time, persons which received public signs of their success or excellence from a state or from professional societies (Nobel prize winners, Oscar or popular competitions winners, members of national academies, etc) live longer than ordinary citizens [8-14].

We analyzed the data on age of death mentioned in Wikipedia 57914 males professionally involved in the 25 of sport disciplines (Table 1). There is significant difference in the mean age of death (MAD) between some of them. Thus, maximum MAD was in yachtsmen (sailors) $(77.1 \pm 0.88$ years) and minimal -in auto- and moto-sportsmen $(62.0 \pm 0.71$ years $)$, that was 15.1 years difference $(\mathrm{p}<0.001)$.

Short living sportsmen included the into 4th quartile of MAD was between 62 and 68 years and were presented by auto- and motorsport, climbing, wrestling, heavy athletics, football (soccer), and, surprisingly, chess players. It could be suggested that these extremely physically and psychologically hard sport disciplines are responsible for more short life span. However, among of sportsmen related to the second and the third quartiles (68 to 71 years and 71 to 73 years) were observed such energy consuming sport disciplines as the ice hockey, American football, bike, rugby, rowing, basketball, gymnastics, tennis. The longliving sportsmen, related to the $1^{\text {st }}$ quartile ( 73 to 77 years) were involved into "aristocratic" sports (sailing, fencing, equestrian) and also into so hard sports as skis and swimming. Chase et al. [3] studied mortality in 40,547 men age 20-90 years who completed a health examination during 1971-2003. Total of 3,386 death occurred during 543,330 man-years of observation. After adjustment for age, body- mass index, smoking status, alcohol intake, and family history of cardiovascular disease, swimmers had 53\%,50\%, and 49\% lower allcause mortality risk than did men who were sedentary, walkers, or runners, respectively ( $\mathrm{p}<0.05$ for each).

It is worthy of note that the sportsmen of the 1st quartile more frequently survive the age of 90 -years $-14,56 \%$ (10\% to $19 \%)$ than the $2^{\text {nd }}$ quartile $-11,26 \%$ (9\% to $\left.14 \%\right)$ or the $3^{\text {rd }}-7,11 \%(5 \%$ to $15 \%)$ and $4^{\text {th }}-4,70 \%$ ( $4 \%$ to $\left.10 \%\right)$. Practically, the same ratio was observed for sportsmen survived 100 and more years: $1,11 \% ; 0,79 \% ; 0,33 \%$ and $0,17 \%$ in 1 st to 4 th quartiles (Table 1 ).

We have analyzed the incidence of violent death among persons involved into various sports.

Incidence of suicides was maximal among tennis players (12.0\%) and minimal $(0.08 \%)$ in rowing sportsmen. The rate of accidentdependent death was maximal among climbing and auto-motosportsmen (34.3\% and 30.27\%) that correlate with high risk of traumas in these sports. $14.7 \%$ of accidence death was among skis sportsmen, $9.88 \%$ of accident death was among bike riders, and $8.29 \%$ at equestrain sports and minimal-among fields hockey (1.00) and cricket players (1.13).

In comprehensive review on mortality and longevity in elite athletes [6] it was shown significant differences depending on sport specialty. An important challenge to mortality research in sport is the lack of data on the health behavior of athletes post retirement. Teramoto and Bugnum [2] found a trend towards endurance (e.g., long-distance runners) and mixed-sport (e.g. soccer) athletes having more favorable survival outcomes relative to power sport (e.g. weightlifters) athletes and the general population. Our preliminary analysis of mean age of death, longevity and incidence of violent death (suicide and accident) shows that their variability depends not only on energy flow and intensity but also on psychological factors which are significant for success and victory in each sport discipline. We are open for collaboration in analyses of our database on sportsmen involved in various sport. 
Citation: Anisimov VN, Zharinov GM (2017) Mean Age of Death, Longevity and Incidence of Violent Death Among Various Elite Sportsmen

Page 2 of 3

\begin{tabular}{|c|c|c|c|c|c|c|c|c|c|c|}
\hline \multirow[t]{2}{*}{$\begin{array}{l}\text { Sport } \\
\text { category }\end{array}$} & \multirow[t]{2}{*}{$\mathbf{N}$} & \multirow[t]{2}{*}{$\begin{array}{l}\text { Mean age of death } \\
\text { (years) }\end{array}$} & \multicolumn{2}{|c|}{$\begin{array}{l}\text { Persons who lived } \\
90+\text { years }\end{array}$} & \multicolumn{2}{|c|}{$\begin{array}{l}\text { Persons who lived } \\
100+\text { years }\end{array}$} & \multicolumn{2}{|c|}{ Suicides } & \multicolumn{2}{|c|}{ Accidents } \\
\hline & & & Abs. & $\%$ & Abs. & $\%$ & Abs. & $\%$ & Abs. & $\%$ \\
\hline Sailing & 292 & $77.1 \pm 0.88$ & 55 & 18.84 & 10 & 3.42 & 4 & 1.37 & 14 & 4.79 \\
\hline Fencing & 319 & $74.9 \pm 0.85$ & 44 & 13.79 & 1 & 0.31 & 3 & 0.94 & 7 & 2.19 \\
\hline Skis & 336 & $74.6 \pm 0.87$ & 53 & 15.77 & 2 & 0.60 & 1 & 0.30 & 14 & 4.17 \\
\hline Shooting & 340 & $73.9 \pm 0.84$ & 50 & 14.71 & 2 & 0.59 & 5 & 1.47 & 9 & 2.65 \\
\hline Equestrian & 434 & $73.0 \pm 0.89$ & 72 & 16.59 & 5 & 1.15 & 11 & 2.53 & 36 & 8.29 \\
\hline Swimming & 525 & $72.8 \pm 0.70$ & 53 & 10.10 & 5 & 0.95 & 4 & 0.76 & 16 & 3.05 \\
\hline Athletics & 1509 & $72.7 \pm 0.45$ & 225 & 14.91 & 22 & 1.46 & 22 & 1.46 & 59 & 3.91 \\
\hline Rugby & 3074 & $72.5 \pm 0.30$ & 318 & 10.34 & 5 & 0.16 & 32 & 1.04 & 59 & 1.92 \\
\hline Golf & 679 & $71.6 \pm 0.61$ & 75 & 11.05 & 5 & 0.74 & 8 & 1.18 & 9 & 1.33 \\
\hline Gymnastics & 445 & $71.6 \pm 0.79$ & 47 & 10.56 & 11 & 2.47 & 5 & 1.12 & 6 & 1.35 \\
\hline Field hockey & 498 & $71.6 \pm 0.72$ & 46 & 9.24 & 2 & 0.40 & 3 & 0.60 & 5 & 1.00 \\
\hline Rowing & 1275 & $70.9 \pm 0.49$ & 131 & 10.27 & 4 & 0.31 & 1 & 0.08 & 27 & 2.12 \\
\hline Basketball & 2026 & $70.8 \pm 0.38$ & 205 & 10.12 & 11 & 0.54 & 19 & 0.94 & 58 & 2.86 \\
\hline Tennis & 653 & $70.6 \pm 0.70$ & 79 & 12.10 & 8 & 1.23 & 11 & 1.68 & 23 & 3.52 \\
\hline Bike & 749 & $70.3 \pm 0.74$ & 112 & 14.95 & 5 & 0.67 & 15 & 2.00 & 74 & 9.88 \\
\hline American football & 5151 & $70.2 \pm 0.23$ & 395 & 7.67 & 18 & 0.35 & 46 & 0.89 & 152 & 2.95 \\
\hline Baseball & 9810 & $68.2 \pm 0.17$ & 650 & 6.63 & 30 & 0.31 & 80 & 0.82 & 210 & 2.14 \\
\hline Cricket & 8614 & $68.1 \pm 0.18$ & 481 & 5.58 & 18 & 0.21 & 35 & 0.41 & 118 & 1.37 \\
\hline Ice hockey & 2454 & $67.9 \pm 0.35$ & 150 & 6.11 & 3 & 0.12 & 24 & 0.98 & 120 & 4.89 \\
\hline Chess & 1250 & $67.3 \pm 0.45$ & 69 & 5.52 & 3 & 0.24 & 11 & 0.88 & 24 & 1.92 \\
\hline Football (soccer) & 14586 & $67.1 \pm 0.14$ & 582 & 3.99 & 16 & 0.11 & 94 & 0.64 & 512 & 3.51 \\
\hline Heavy athletics & 394 & $64.6 \pm 0.96$ & 21 & 5.33 & 2 & 0.51 & 3 & 0.76 & 18 & 4.57 \\
\hline Wrestling & 1119 & $63.4 \pm 0.56$ & 57 & 5.09 & 2 & 0.18 & 39 & 3.49 & 60 & 5.36 \\
\hline Climbing & 414 & $63.0 \pm 1.04$ & 41 & 9.90 & 5 & 1.21 & 6 & 1.45 & 142 & 34.30 \\
\hline Auto and Motorsport & 968 & $62.0 \pm 0.71$ & 75 & 7.75 & 4 & 0.41 & 21 & 2.17 & 293 & 30.27 \\
\hline
\end{tabular}

Table 1: Variation in mean age of death of sportsmen, rate of long-livers sportsmen and incidence of violence death among them.

\section{References}

1. Schulz-Aellen MF (1997) Aging and human longevity. Boston: Birkhauser, USA.

2. Teramoto M, Bungum TJ (2010) Mortality and longevity of elite athletes. J Sci Med Sport 13: 410-416.

3. Chase NL, Sui X, Blair SN (2008) Swimming and all-cause mortality risk compared with running, walking, and sedentary habits in men. Int J Aquatic Res Educ 2: 213-223.

4. Kujawska A, Topka W, Gajos M, Androsiuk PJ, Perlowski R, et al. (2017) Do former elite athletes live longer? Potential role of critical window(s) in the development of the health-oriented behaviors and physiological adaptation. J Educ Health Sport 7: 11-21.
5. Lee-Heidenreich J, Lee-Heidenreich D, Myers J (2017) Differences in life expectancy between Olympic high jumpers, disc throwers, marathon and 1`00 meter runners. BMC Sports Sci Med Rahabilitation 9: 3.

6. Lemez S, Baker J (2015) Do elite athletes live longer? A systematic review of mortality and longevity in elite athletes. Sports Medicine 1: 16.

7. Wattie N, Lemez S, Ci A, Rotondi M, Baker J (2016) Does early career achievement lead to earlier death? Assessment of the precocity-longevity effect in professional basketball players. Front Public Health 4: 258.

8. Anisimov VN (2008) Molecular and physiological mechanisms of aging. (2nd edn), Vols. 1 and 2, Nauka, St. Petersburg, Russia.

9. Finch CE (1990) Longevity, senescence, and the genome. University Chicago Press, Chicago, USA. 
Citation: Anisimov VN, Zharinov GM (2017) Mean Age of Death, Longevity and Incidence of Violent Death Among Various Elite Sportsmen Categories . J Gerontol Geriatr Res 6: e148. doi:10.4172/2167-7182.1000e148

Page 3 of 3

10. Anisimov VN, Michalski AI (2004) Are Nobel prize winner getting older?" Mathematical analysis of age and life span of the Nobel prize winners. Adv Gerontol 15: 14-22.

11. Andreev EM, Jdanov D, Shkolnikov VM, Leon DA (2011). Long-term trends in the longevity of scientific elites: Evidence from the British and the Russian academies of science. Popul Stud (Camb) 65: 319-334.
12. Redelmeier DA, Singh S (2001) Survival in academy award-winning actors and actresses. Ann Intern Med 134: 955-962.

13. Anisimov VN, Zharinov GM (2013) Life span and longevity in representatives of creative professions. Adv Gerontol 26: 405-416.

14. Anisimov VN, Zharinov GM (2013) Muses and longevity. J Gerontol Geriatr Res 2: e123. 